Sandra Regina Martini ${ }^{1}$

Marina Sanches Wünsch ${ }^{2}$

\title{
COOPERAÇÃO INTERNACIONAL E EFETIVAÇÃO DO DIREITO À SAÚDE: UMA ANÁLISE A PARTIR DA AGENDA DO BRICS
}

International cooperation and the achievement of the right to health: an analysis of the BRICS agenda

${ }^{1}$ Centro Universitário Ritter dos Reis. Porto Alegre/RS, Brasil.

${ }^{2}$ Universidade Federal do Rio Grande do Sul. Porto Alegre/RS, Brasil.

Correspondência: Sandra Regina Martini. E-mail: srmvial@terra.com.br.

Recebido em: 12/09/2016. Revisado em: 09/11/2016. Aprovado em: 11/11/2016. 


\section{RESUMO}

O presente estudo pretende efetuar uma análise do potencial que a cooperação política entre Brasil, Rússia, China, Índia e África do Sul - países que compõem o Brics - tem de fomentar uma agenda pautada também na efetivação de direitos humanos. Acredita-se que a cooperação internacional seja um instrumento fraterno capaz de acelerar o processo de efetivação dos direitos humanos e que, por meio dela, seja possível não apenas buscar o desenvolvimento econômico, mas também, de fato, efetivar direitos, especialmente os direitos humanos. Nesse sentido, parte-se da ideia de que o marco da agenda de cooperação do Brics apresenta-se como uma possibilidade concreta de novas formas de cooperação internacional, pois se trata de um grupo de países distantes geograficamente, mas que visualizam na cooperação o fortalecimento das relações internacionais. Ademais, essa nova agenda de cooperação atribui um papel de destaque ao direito à saúde, representando um direito social básico para o desenvolvimento humano, que rompe fronteiras ao superar a barreira de Estados soberanos e, assim, possibilita a criação de consensos e pactos.

\section{Palavras-Chave}

Brics; Cooperação Internacional; Direito à Saúde; Fraternidade.

\section{ABSTRACT}

This paper intends to analyze the potential of the political cooperation between Brazil, Russia, China, India and South Africa, country members of BRICS, of fostering an agenda also based on the achievement of human rights. International cooperation is believed to be a fraternal instrument capable of accelerating the achievement of human rights, it enables not only economic development but also the realization of rights; in particular, human rights. In this sense, the idea starts to take shape that the cooperation agenda framework of BRICS provides a real possibility for new forms of international cooperation, and despite of being a group of countries geographically distant from each other, they regard cooperation as the strengthening of international relations. Furthermore, this new cooperation agenda attributes an important role to the right to health, representing a primary social right for human development, which breaks boundaries, contributes in overcoming barriers between sovereign States and, in this way, allows the creation of a consensus and of pacts.

\section{Keywords}

Brics; Fraternity; International Cooperation; Right to Health. 


\section{Introdução}

Nas últimas décadas, vivenciamos o aprofundamento do processo de globalização e da interdependência entre Estados, especialmente em consequência da evolução tecnológica - a maior capacidade de transmissão e os softwares de tecnologia da informação e comunicação têm barateado cada vez mais a separação geográfica das etapas de produção e o intenso fluxo de capitais. Esse processo em curso afeta, em diferentes graus, todas as esferas da sociedade, bem como as relações internacionais, ao aproximar países geograficamente distantes.

Tais transformações obrigam os Estados a buscarem novas formas de se organizar nessa realidade. Um exemplo disso é o surgimento de integrações regionais, entre as quais a mais recente é a do Brics, grupo ${ }^{1}$ de países emergentes - Brasil, Rússia, Índia, China e África do Sul - cujo papel se torna cada vez mais relevante no âmbito das relações internacionais e na sociedade atual, principalmente no debate acerca da possível reorganização da ordem global e da transição para um mundo multipolar.

Um dos principais reflexos da globalização é a redefinição do papel desempenhado pelo Estado-Nação, pois essa nova sociedade é marcada pela complexidade e pela indeterminação, elementos que passam a constituir o Estado contemporâneo. Ao mesmo tempo, a noção tradicional de Estado soberano como detentor do monopólio da força tende a dar lugar a uma nova lógica de interdependência e cooperação, apagando a separação entre assuntos internos e externos ${ }^{2}$.

Ainda como resultado desse intenso processo, passamos a compreender, especialmente a partir dos anos 1990, que o desenvolvimento econômico não dá conta de resolver todas as mazelas da sociedade - por exemplo, o problema da redistribuição da renda - e ressalta nossa falta de articulação da solidariedade ${ }^{3}$. A mudança para um mundo multipolar economicamente globalizado tem mostrado o desafio para efetivação da cidadania perante o enfrentamento do endividamento, da hegemonia do setor financeiro, do desemprego estrutural, da diferença na qualidade do desenvolvimento entre os países e de suas respectivas capacidades para gerenciar as crises econômicas e sociais internas.

Esse é, justamente, o desafio do Brics: buscar um modelo de cooperação que conduza à resolução participativa dos principais problemas internacionais, com o objetivo de eliminar desequilíbrios, garantir estabilidade política e proporcionar condições para a resolução dos desafios de uma sociedade cosmopolita - o que, portanto, perpassa pela efetivação de direitos humanos. Acredita-se que somente

\footnotetext{
${ }^{1}$ Neste artigo, utilizaremos os termo "grupo" e "grupo político" para denominar o Brics. Nesse sentido, tratase mais de um recurso para nomear o conjunto de países do que exatamente uma preferência por esta ou aquela definição dos autores e seus textos abordados.

${ }^{2}$ CHEVALLIER, Jacques. O Estado pós-moderno. Tradução Marçal Justen Filho. São Paulo: Fórum, 2009. p. 21. 3INNERARITY, Daniel. Ética de la hospitalidad. Barcelona: Península, 2001. p. 87.
} 
a convergência do econômico com a efetivação de direitos humanos possibilitará, de fato, a redução das desigualdades sociais e estruturais nos países-membros do grupo, bem como das desigualdades no plano internacional. Assim, aos países do Sul é atribuído um papel cada vez mais relevante no cenário internacional.

A fim de contribuir para que novas discussões sejam levantadas nesse contexto e para que alguns paradigmas possam ser superados, este artigo objetiva estudar a temática do direito à saúde no contexto do Brics. Acredita-se que o Brics, por ser um grupo político que surge em um contexto histórico diverso dos demais blocos econômicos - que é reflexo dessa atual sociedade em rede, conectada -, pode contribuir para a formulação de um novo modelo de cooperação, que busca efetivamente reduzir as assimetrias entre os países por meio de uma agenda de cooperação que objetive também dar efetividade aos direitos humanos, recém-garantidos internamente por esses países.

O que pode aproximar os países do Brics? O que pode ser codividido? É realmente possível construir uma aproximação? Estes questionamentos movem o presente artigo. Para refletirmos e aprofundarmos cientificamente o tema, elegemos os direitos humanos a partir de uma perspectiva fraterna. E como é possível pensar na fraternidade nesse contexto? Esta é a pergunta fundamental do artigo. Para responder a ela, trabalharemos com a Metateoria do Direito Fraterno, o que nos leva imediatamente a outro questionamento: no atual contexto global, é possível, ainda, existir espaço para a fraternidade? Para tentarmos responder a este questionamento, é necessário retomarmos o conceito de fraternidade de Rest $a^{4}$.

A partir desse conceito, antigo e esquecido, Eligio Resta propõe uma nova abordagem para os fenômenos sociojurídicos. É uma teoria livre de preconceitos e conceitos advindos de outras áreas que não a científica. Assim, o autor busca no conceito original as ideias do compartilhar, do pactuar, da lei da amizade, do universalismo, da inclusão sem limites; esses indicativos mostram que é necessário ver o outro como um outro-eu. O eu-outro e o outro-eu operam constantemente na proposta de transformação social, pois o Direito Fraterno é a relação entre vida e direito, e a vida em comunidade é o sujeito e objeto da experiência jurídica.

Sendo desvelador de paradoxos, o código fraterno pode ser uma importante ferramenta de análise: a cooperação entre os países do Brics não necessariamente precisa seguir a lógica tradicional dos grupos e mercados comuns cuja relação central é meramente econômica ou economicista -- embora o grupo tenha objetivos econômicos como "pedra fundante", o que possibilitaria a reprodução de alguns insucessos no avanço dos direitos humanos -, e sim ter o direito à saúde como um de seus principais propulsores. Trabalhar com a Metateoria do Direito Fraterno

${ }^{4}$ RESTA, Eligio. O direito fraterno. Tradução e coordenação de Sandra Regina Martini. Santa Cruz do Sul: EDUNISC, 2004. 
não significa fazer uma análise superficial dos fenômenos, mas sim sempre buscar nos limites uma nova possibilidade. A conclusão possível, nessa reflexão, é mostrar novas possibilidades de cooperação internacional, fundada em outros pressupostos que não apenas os interesses econômicos.

Portanto, este artigo pretende apresentar um conjunto de reflexões e indagações e dar a dimensão dos desafios que se apresentam ao Brics, especialmente quando se trata da consolidação de uma agenda que visa à efetivação de direitos humanos e que reflete a importância de pensar o direito à saúde como uma "ponte" para aproximar os países. Nesse sentido, advoga-se que a saúde, por não ter fronteiras (como evidenciam doenças facilmente propagadas), por se tratar de um direito intersetorial e, além disso, por estar diretamente vinculada à promoção dos demais direitos humanos, seja uma ponte/exemplo de como a cooperação pode contribuir para a efetivação desses direitos nessa nova agenda de cooperação que surge com o Brics.

\section{Cooperação internacional e o papel do Brics: como é possível haver um único locus dos direitos humanos?}

No espaço global, os direitos se dilatam e desaparecem, se multiplicam e se empobrecem, oferecem oportunidades coletivas e se fecham no âmbito individual, redistribuem os poderes e sofrem sujeições, sobretudo os imperativos de segurança e a tirania do mercado 5 . (Tradução livre.)

O Brics é uma oportunidade inédita para esses países identificados como "potências emergentes", culturas, políticas e economias, o que contribuí para transformar as práticas acadêmicas vinculadas aos países "colonizadores". Nesse sentido, importantes estudos acadêmicos sobre os países do Brics favorecem uma mudança no imaginário desses países sobre si mesmos e de como outros países os reconhecem. Esse compartilhar de culturas e tradições pode criar novos espaços, novos canteiros para a fraternidade - levando sempre em consideração que esse aspecto não tem sido o ponto alto das cooperações que ocorreram até hoje, mas, exatamente por isso, entendemos que é fundamental o resgate desse novo/velho conceito também no Brics.

Os próprios países do Brics denominam-se um grupo que visa a contribuir para o desenvolvimento da humanidade e para o estabelecimento de um mundo mais justo e equânime. Os trabalhos do grupo iniciaram-se, de fato, em 2006, fruto

\footnotetext{
${ }^{5}$ No original: "Nello spazio globale $i$ diritti si dalatano e scompaiono, si moltiplicano e si impoveriscono, offrono opportunità colletive e si rinserrano nell'ambito individuale, redistribuiscono poteri e subiscono soggezioni, soprattutto agli imperativi della sicurezza e alla prepotenza del mercato." RODOTÀ, Stefano. II diritto di avere diritti. Bari: Laterza, 2012. p. 36.

${ }^{6}$ VISENTINI. Paulo Fagundes. Brics, OCX e Ibas: as coalizões dos emergentes. In: VISENTINI. Paulo et al. (Orgs.). Brics, as potências emergentes. 1. ed. Petrópolis: Vozes, 2013. p. 199.
} 
de um impulso externo que apontou os integrantes do Brics como potências emergentes em função de seu potencial de desenvolvimento econômico. Assim, o surgimento da sigla Brics não parte de uma ideia comum de seus países-membros, mas foi incorporada por eles. Durante a $61^{\text {a }}$ Assembleia Geral da ONU esse grupo de países deu início à articulação internacional de cooperação para o desenvolvimento.

Assim, desde já, percebe-se como a comunicação e a informação, segundo Innerarity ${ }^{7}$, são o grande alimento do protesto social, na medida em que aumentam as possibilidades de se conhecer a própria situação e compará-la com outras. O fato de os países do Brics vislumbrarem uma mudança na definição de ricos e pobres no cenário internacional faz com que o justo deixe de ser definível a priori. Ou seja, nessa sociedade complexa, as posições relativas dos diferentes indivíduos e grupos são sempre discutíveis.

O desafio que se apresenta hoje é: como efetivar o que está escrito nos acordos e tratados? Como levar a sério o desenvolvimento da humanidade por meio da própria humanidade? Na reflexão de Resta, vemos que, embora a sociedade até hoje tenha apostado na soberania do econômico ou do político, é possível ver o "outro lado" e apostar em novas formas de compartilhar a vida social. Com relação ao papel do jurista nesse contexto, segundo Resta: "o jurista tem a tarefa de desmantelar a categoria de soberania dos Estados, que está na base da guerra, o egoísmo do território"s. Desse modo, a fraternidade contribui para se repensar o papel do Estado - o atual e aquele que pode vir a desempenhar -, buscando especificamente romper com a ideia de um Estado soberano paterno para a construção de um Estado fraterno, no qual a humanidade represente um lugar comum (e não algo restrito aos confins dos Estados nacionais), onde novas formas de convivência podem ser experimentadas. Ademais,

as doenças não respeitam os limites territoriais. Elas se alastram sem pedir licença e, se continuarmos adotando medidas regionais, não conseguiremos eliminar determinadas doenças; por isso o Direito Fraterno é fundamental para enfrentar os problemas da nudavita?

Em maio de $2008^{10}$, os ministros das Relações Exteriores do Brasil, da Rússia, da Índia e da China reuniram-se em Ecaterimburgo, na Rússia, e emitiram um comunicado conjunto em que ressaltaram a importância da construção de um sistema internacional fundado no estado de direito e na diplomacia multilateral.

\footnotetext{
${ }^{7}$ INNERARITY, Daniel. op. cit., p. 87.

${ }^{8}$ RESTA, Eligio. 0 direito fraterno, cit., p. 12.

${ }^{9}$ VIAL, Sandra Regina Martini. O pressuposto da fraternidade como condição para a efetivação do direito à saúde. In: AITH, Fernando et al. (Orgs.). Direito sanitário: saúde e direito, um diálogo possível. Belo Horizonte: Escola de Saúde Pública do Estado de Minas Gerais, 2010. p. 119.

${ }^{10}$ BRICS. Reunião dos Ministros das Relações Exteriores em Ecaterimburgo, 2008. Ecaterimburgo, 16 de maio de 2008. Disponível em: <http://brics.itamaraty.gov.br/pt-br/categoria-portugues/20-documentos/184-reuniaodos-ministros-das-relacoes-exteriores-em-ecaterimburgo-2008>. Acesso em: 01 out. 2013.
} 
Embora o interesse velado dessa cooperação não fosse necessariamente uma “cooperação", mas uma competição entre os países utilizando a ideia de amizade entre nações (no sentido de poder superar as barreiras geográficas) para reforçar as economias mais fortes do bloco, nosso objetivo é chamar atenção para a fraternidade, que apesar de estar escondida, pode ser encontrada no questionamento da efetivação dos direitos humanos. Os países do Brics também observaram que a cooperação Sul-Sul é um elemento importante nos esforços internacionais para o desenvolvimento. Ademais, às drásticas transformações no caráter da sociedade internacional, agregou-se a ideia de que a sociedade internacional deve ir além da simples coexistência entre os Estados nacionais; é preciso incorporar uma gama de princípios acordados internacionalmente, como os relativos aos direitos humanos e à democracia, aos limites do uso da força e à sustentabilidade ambiental, e refletir sobre eles ${ }^{11}$.

No ano seguinte, em 2009, foi realizada a primeira Cúpula do Brics - hoje já em sua sétima edição. Ocorre que, a partir do momento em que os Estados aceitam cooperar, é necessária a criação de estruturas e mecanismos para que essa cooperação aconteça.

Além disso, é preciso definir qual modelo de cooperação esses países estão dispostos a assumir, pois eles é que arcarão com os custos e as limitações que dela derivarem - e isso não é uma tarefa fácil, pois os investimentos e interesses de cada país-membro podem ser distintos. Essas diferenças entre os países não devem significar distanciamentos, e sim aproximações. De uma perspectiva sanitária social, são essas distinções que podem contribuir para a efetivação dos direitos humanos.

Cumpre ressaltar que o Brics não se trata de integração, mas de cooperação, pois nesta ainda prevalecem os interesses nacionais. Em outras palavras, a cooperação é uma forma de promover as relações interestatais, enquanto que, na integração, prevalece a proteção dos interesses comuns. Por isso, e também porque ainda não existem órgãos institucionalizados no Brics, ainda é muito cedo para denominar o Brics de bloco - "o bloco não se apoia em nenhum reconhecimento formal e é caracterizado por uma estrutura hierárquica"12. A tendência é um processo de expansão das regras, recentemente simbolizado pelo Novo Banco de Desenvolvimento (NBD), institucionalizado em julho de 2014 pelo grupo e que pretende financiar os primeiros projetos de desenvolvimento sustentável em países pobres. O cuidado que precisamos ter com essa nova forma de cooperação é que ela seja de fato uma cooperação: sem permitir a exploração dos países mais frágeis economicamente, criando formas de

\footnotetext{
${ }^{11}$ HURREL, Andrew. Hegemonia, liberalismos e ordem global: qual é o espaço para potências emergentes? In: HURREL, Andrew et al. (OrgS.). Os Brics e a ordem global. Rio de Janeiro: FGV, 2009. p. 13-14.

${ }^{12}$ BONANATE, Luigi. Política dos Blocos. In: BOBBIO, Norberto; MATTEUCCI, Nicola; PASQUINO, Gianfranco (Orgs.). Dicionário de política. Tradução de Carmen C. Varriale et al. 12. ed. Brasília-DF: Ed. da UnB; São Paulo: Imprensa Oficial do Estado, 2002. p. 113.
} 
compartilhar com o outro como se fosse um outro-eu, pressuposto fundamental da Metateoria do Direito Fraterno. Explica Resta que o Direito Fraterno:

trata-se de um modelo de direito que abandona a fronteira fechada da cidadania e olha em direção à nova forma de cosmopolitismo, que não é representada pelos mercados, mas pela necessidade universalista de respeito aos direitos humanos que vai se impondo ao egoísmo dos "lobos artificiais" ou dos poderes informais que à sua sobra governam e decidem ${ }^{13}$.

Portanto, fica evidente que os países do Brics têm estreitado laços de cooperação para financiar atividades de desenvolvimento entre os países do sul. Todavia, também é sabido que os países do Brics convivem com desequilíbrios econômicos e sociais internos. Assim, devido ao grau de influência e representatividade política desses países em suas regiões, é fundamental que, além do desenvolvimento econômico que almejam, eles se comprometam com agendas políticas e programas de cooperação para proteção dos direitos humanos, uma vez que nem sempre o desenvolvimento econômico representa uma maior efetividade dos direitos sociais. Segundo Innerarity:

La convergencia de lo económico y lo social no es automática. La pobreza actual resulta especialmente insólita porque finaliza decenios de aparente homogeneización de la sociedad impulsada por el irreversible crecimiento económico ${ }^{14}$.

Os próprios dados apresentados pelos países do Brics dão conta de demonstrar que, apesar de o grupo almejar e vir conquistando mais desenvolvimento econômico e maior influência política, seus indicadores sociais tiveram uma queda entre o surgimento do bloco, em 2006, até 2012, enquanto deveriam estar subindo. O Índice de Desenvolvimento Humano (IDH) de 2007 a 2012 nos países do Brics retrocedeu, segundo os relatórios do Programa das Nações Unidas para o Desenvolvimento (PNUD): a África do Sul passou de 0,683 para 0,629, mas se manteve com índice médio; outros dois países que são considerados medianos são China (que retrocedeu de 0,772 para 0,699) e Índia (que foi de 0,612 para 0,554); países como Brasil e Rússia, cujo IDH é considerado elevado, também retrocederam nesse período (Brasil de 0,813 para 0,730 , e Rússia de 0,817 para 0,788 $)^{15}$. Em 2014, o IDH de todos os países do grupo voltou a melhorar: Rússia 0,798; Brasil 0,755; África do Sul 0,666; Índia 0,609; e China 0,727 .

\footnotetext{
${ }^{13}$ RESTA, Eligio. O direito fraterno, cit., p. 16.

${ }^{14}$ INNERARITY, Daniel. op. cit., p. 88.

15PROGRAMA DAS NAÇÕES UNIDAS PARA O DESENVOLVIMENTO (PNDUD). Os objetivos de desenvolvimento do milênio. Brasília, DF, 2012. Disponível em: <http://www.pnud.org.br/ODM.aspx>. Acesso em: 21 jul. 2013.

${ }^{16}$ PROGRAMA DAS NAÇÕES UNIDAS PARA O DESENVOLVIMENTO (PNDUD). Relatório do Desenvolvimento Humano de 2015. Brasília, DF, 2015. Disponível em: <http://www.br.undp.org/content/brazil/pt/home/ library/relatorios-de-desenvolvimento-humano/relatorio-do-desenvolvimento-humano-200014.html>. Acesso em: 30 out. 2017.
} 
Outro dado interessante diz respeito ao percentual do Produto Interno Bruto (PIB) que esses países disponibilizam para despesas totais em saúde. Considerando os dados de 2006 e 2009, apenas dois dos cinco países aumentaram o percentual de investimento em saúde: o Brasil, cujo percentual em 2006 era de 7,2\% do PIB e passou para 9\% em 2009 (e para 9,7\% em 2014); e a Índia, que foi 3,4\% para 4,2\%, respectivamente nesses mesmos anos (embora tenha voltado a diminuir para $4 \% \mathrm{em}$ 2014). Já os outros três países tiveram uma redução: a África do Sul, de 9,9\% para $8,5 \%$; a China reduziu drasticamente, de $9,9 \%$ para $4,6 \%$; assim como a Rússia, de $10,8 \%$ para $5,4 \%$ em $2009{ }^{17}$. No caso destes três últimos, houve em 2014 um pequeno crescimento: na África do Sul, para 8,9\%; na China, para 5,6\%; e na Rússia, para $6,5 \%$ - porém, por mais que tenham sido elevados, continuam ainda insuficientes ${ }^{18}$.

Esses dados refletem a prevalência do desenvolvimento econômico e do direito de livre comércio sobre os direitos humanos, especialmente sobre os sociais e econômicos. Segundo Ventura ${ }^{19}$, o problema muitas vezes está no peso diferente dado aos organismos internacionais: os de natureza econômica desfrutam de maior poder do que aqueles que atuam no campo da saúde, por exemplo. Assim, a única forma de evitar esse conflito é fazer com que os direitos humanos e os direitos econômicos sejam permeáveis. Como afirma Amartya Sen:

Um entendimento econômico adequado das causas e maneiras de prevenir as fomes coletivas, com a devida avaliação da multiplicidade de causas econômicas e políticas envolvidas, mostra como é ingênua uma concepção da fome baseada mecanicamente na disponibilidade de alimentos ${ }^{20}$.

A mudança para um sistema multipolar economicamente globalizado tem mostrado que mais precisa ser feito para se enfrentar o endividamento, a hegemonia do setor financeiro, o desemprego estrutural, a diferença na qualidade do desenvolvimento entre os países e suas respectivas capacidades para gerenciar as crises econômicas e sociais internas. Seguindo na ideia de Sen:

A distribuição dos benefícios das relações globais depende não só das políticas internas, mas também de um leque de arranjos sociais internacionais, incluindo tratados comerciais, leis de patentes, iniciativas sobre saúde global, convênios educativos internacionais, centros de disseminação tecnológica $[\ldots]^{21}$.

\footnotetext{
${ }^{17}$ PROGRAMA DAS NAÇÕES UNIDAS PARA O DESENVOLVIMENTO (PNDUD). Os objetivos de desenvolvimento do milênio, cit.

${ }^{18}$ PROGRAMA DAS NAÇÕES UNIDAS PARA O DESENVOLVIMENTO (PNDUD). Relatório do Desenvolvimento Humano de 2015, cit.

${ }^{19}$ VENTURA, Deisy de Freitas Lima. Uma visão internacional do direito à saúde. In: SOUSA JUNIOR, José Geraldo de; FONSECA, Lívia Gimenes Dias da; APOSTOLOVA, Bistra Stefanova (Orgs.). O direito achado na rua. Brasília, DF: CEAD/UNB, 2008. v. 4, p. 84.

${ }^{20}$ SEN, Amartya. A ideia de justiça. São Paulo: Companhia das letras, 2011. p. 424-425.

${ }^{21}$ Id. Ibid., p. 444.
} 
É preciso um modelo de cooperação que conduza a processos participativos de resolução dos principais problemas internacionais e cujo objetivo seja resolver os desequilíbrios, garantir a estabilidade política e proporcionar as condições para a superação dos desafios de uma sociedade cosmopolita. Pensar essa agenda abre caminho para novos modelos de cooperação internacional, em uma ordem mundial menos desigual, mais participativa e estável. Esses novos modelos exigem resposta em nível global, porém tal resposta não pode continuar sendo uma não cooperação ou uma forma de exploração entres nações.

\section{A Agenda do Brics de 2009 a 2015 e o tema dos direitos humanos e do direito à saúde}

[...] deve-se escavar em torno da linguagem jurídica o sentido sugerido pela singular relação entre vida e direito, na dupla versão da vida no direito e da vida do direito, e das suas complicadas interseções da vida [...] e nas grandes Cartas Constitucionais irrompem, já há tempo, dimensões nem sempre imateriais da vida como a felicidade, a vida das futuras gerações, a fraternidade ${ }^{22}$.

Assim, o Direito Fraterno pretende fornecer uma nova hipótese de análise do direito, especialmente em um cenário em que a "forma estatal de pertenças fechadas, governadas por um mecanismo ambíguo que inclui cidadãos, excluindo todos os outros" ${ }^{\prime 2}$, entra em tensão. Mas, mais do que isso, o paradoxo se estabelece à medida que "esta sociedade que suprime a distância geográfica, amplia a distância interior, na forma de uma separação espetacular"24, uma vez que o desenvolvimento urbano e industrial acaba por isolar o indivíduo: a sociedade acaba sendo a integração dos isolados em conjunto ${ }^{25}$.

O Brics realizou, até 2015, sete cúpulas dos chefes de Estado e de Governo, que resultaram, portanto, em sete declarações conjuntas dos líderes desses países: a Primeira Cúpula ocorreu na Rússia em 16 de junho de 2009; a Segunda Cúpula, no Brasil em 15 de abril de 2010; a Terceira Cúpula ocorreu na China em 14 de abril de 2011, contou com o ingresso da África do Sul no Brics; a Quarta Cúpula foi realizada na Índia em 29 de março de 2012; a Quinta Cúpula, na África do Sul em 27 de março de 2013; a Sexta Cúpula foi sediada pelo Brasil nos dias 14, 15 e 16 de julho de 2014; e a Sétima Cúpula do Brics ocorreu na Rússia de 26 a 29 de julho de 2015.

Já na Primeira Cúpula, os países do Bric (a África do Sul ainda não participava do grupo) expressaram a vontade de buscar uma reforma das instituições

\footnotetext{
${ }^{22}$ RESTA, Eligio. Diritto vivente. Bari: Laterza, 2013. p.1.

${ }^{23}$ DEBORD, GUY. Sociedade do espetáculo. Rio de Janeiro: Contraponto, 2007. p. 167.

${ }^{24}$ Id., loc. cit.

${ }^{25}$ Id. Ibid., p. 172.
} 
financeiras internacionais, de modo a refletir as transformações da economia mundial. Assim, a principal preocupação expressa em 2009 foi a respeito da situação da economia mundial; no tocante aos direitos humanos, o Bric condenou o terrorismo e reafirmou o compromisso de aumentar a cooperação entre seus países em áreas de interesse social, bem como de fortalecer os esforços para prestar assistência humanitária internacional e reduzir os riscos de desastres naturais ${ }^{26}$.

Cumpre ressaltar que as primeiras áreas a serem afetadas pelas crises econômicas são as sociais, como foi o caso do corte de gastos em assistência técnica em saúde pelos países desenvolvidos pós-crise de 2008. Com um vácuo nesse espaço, o Brics vem aumentando sua influência e fortalecendo programas de assistência. No entanto, o que se espera é que esses programas não reproduzam a lógica tradicional, pois, se o fizerem, não haverá avanços na efetivação de formas fraternas de convivência social.

Para que ocorra uma transformação na agenda global em saúde, é preciso passar de programas de assistência (doador-beneficiários) para programas de cooperação (parcerias), pois somente dessa maneira os países em desenvolvimento superarão as bases de seus problemas sociais e poderão fortalecer suas democracias, além de buscarem realidades socialmente mais equânimes. A cooperação levará, certamente, à construção de uma sociedade mais fraterna, na qual os pactos são estabelecidos entre "irmãos". Para isso, mais uma vez, há a necessidade de entender que a humanidade está ameaçada pela própria humanidade.

A Segunda Cúpula realçou a necessidade de transformações na governança global em todas as áreas relevantes, sem especificar, porém, quais seriam estas áreas. Também reafirmou a necessidade de uma reforma abrangente da Organização das Nações Unidas (ONU), com vistas a torná-la mais eficaz, eficiente e representativa, para que possa lidar com os desafios globais contemporâneos. Com isso, os países do Bric sublinharam seu apoio a uma ordem mundial multipolar, equitativa e democrática, baseada no direito internacional, na igualdade, no respeito mútuo, na cooperação, na ação coordenada e na tomada coletiva de decisões por todos os Estados $^{27}$. No entanto, falar em governança global na saúde é discutir como é possível superar a primazia dos interesses do comércio e do lucro. Como explica Buss:

Os sistemas de saúde dos países em desenvolvimento são submetidos à forte pressão do comércio internacional de insumos para a saúde (medicamentos, kits e reativos para diagnóstico, equipamentos e outros insumos). O alto preço dos medicamentos, em

\footnotetext{
${ }^{26}$ BRICS. First Summit: Joint Statement of the BRIC Countries Leaders. Yekaterinburg, 2009. Disponivel em: $<$ http://brics.itamaraty.gov.br/index.php?option=com_content\&view=article\&id=114:first-summit-2\&catid =21:documents\&ltemid=288>. Acesso em: 21 jul. 2013 .

${ }^{27}$ BRICS. II Second Summit: Joint Statement. Brasília, DF, 16 abr. 2010. Disponível em: <http://brics. itamaraty.gov.br/press-releases/21-documents/66-second-summit>. Acesso em: 01 ago. 2012.
} 
grande parte decorrente de um sistema de proteção patentária que enxerga apenas os interesses das grandes empresas privadas, é um impedimento importante ao acesso dos países pobres e das populações mais pobres dos países de renda média a medicamentos e insumos essenciais para a saúde ${ }^{28}$.

Por isso, uma mudança nesse cenário passa pelos países em desenvolvimento e por mudanças políticas no âmbito das organizações internacionais, especialmente da Organização Mundial da Saúde (OMS). Uma forma de reduzir drasticamente os preços dos medicamentos é aumentar a produção de genéricos, ou seja, a produção de genéricos é uma espécie de contrapartida social em relação aos lucros da indústria farmacêutica. Importante destacar que é com essa ênfase que o Brics vem reforçando sua agenda ao tratar do tema acesso a medicamentos.

Já em 2010, o Bric dedicou uma parte de sua declaração ao desenvolvimento no âmbito social, dando destaque à Declaração do Milênio das Nações Unidas e à necessidade de alcançar os Objetivos do Milênio (ODM). Assim, naquele ano, começaram a aparecer mais claramente temas como desenvolvimento, direitos sociais, redução das desigualdades e solidariedade. Além disso, a cúpula de 2010 trouxe algumas medidas concretas - entre elas, cooperação técnica e apoio financeiro - para contribuir com a consecução do desenvolvimento social sustentável, proteção social, pleno emprego e políticas e programas de trabalho digno dando especial atenção aos grupos mais vulneráveis, como os pobres, as mulheres, os jovens, os migrantes e as pessoas com deficiência ${ }^{29}$. Também foi a primeira vez em que se verificaram iniciativas setoriais que visavam ao reforço da cooperação - por exemplo, o I Programa de Intercâmbio de Magistrados e Juízes dos países do Bric, realizado em março de 2010 no Brasil, após a assinatura, em 2009, do protocolo de intenções entre as supremas cortes dos países ${ }^{30}$. Essas intenções precisam se transformar em ações, e o Bric apresenta-se como um terreno fértil para novos desafios, novas apostas mais fraternas. E, quando falamos em fraternidade, não significa uma visão ingênua da

\footnotetext{
${ }^{28}$ BUSS, P. M. Globalização, pobreza e saúde. Ciência e Saúde Coletiva, Rio de Janeiro, v. 12, n. 6, p. 15751589, nov./dec. 2007. Disponível em: <http://www.scielo.br/pdf/csc/v12n6/v12n6a17.pdf>. http:// dx.doi.org/10.1590/S1413-81232007000600019.

${ }^{29}$ BRICS. II Second Summit: Joint Statement. Brasília, DF, 16 abr. 2010, cit.

${ }^{30} \mathrm{O}$ protocolo assinado pelo Supremo Tribunal Federal do Brasil, o Supremo Tribunal da Federação da Rússia, o Supremo Tribunal da Índia e o Tribunal Popular Supremo da China tem como propósito "objetivo é estabelecer a cooperação recíproca, mediante o intercâmbio de informações, e a divulgação de atividades no âmbito das respectivas competências." Esse acordo é um importante passo para a cooperação relativa à proteção dos direitos humanos, uma vez que "prevê a realização de conferências, seminários e outros encontros técnicos e acadêmicos sobre a prática judicial, os direitos humanos, a promoção do acesso à Justiça, a utilização de métodos alternativos de solução de controvérsias e a proteção de menores, além da aproximação entre seus magistrados." BRICS. Disponível em: <http://www2.stf.jus.br/ portalStfInternacional/cms/verConteudo.php?sigla=portalStfCooperacao_pt_br\&idConteudo=159618>. Acesso em: 1 ago. 2012.
} 
realidade, mas uma visão de transformação possível, ainda que apresente muitas dificuldades - que, por sua vez, requerem a força não violenta da fraternidade.

$\mathrm{Na}$ Terceira Cúpula, percebe-se que o discurso visava a fortalecer os laços de cooperação do Brics (aqui com o ingresso da África do Sul) como um grupo de importante papel no cenário mundial. A declaração de 2011 expressou que:

É o forte desejo comum por paz, segurança, desenvolvimento e cooperação que uniu os países do Brics, com uma população de cerca 3 bilhões de cidadãos de diferentes continentes. O Brics visa a contribuir para o desenvolvimento da humanidade e para o estabelecimento de um mundo mais justo e equânime ${ }^{31}$.

Contudo, o intuito não era restringir-se ao grupo, pois, ao mesmo tempo, o texto afirmava que a cooperação é inclusiva, sem elemento de confronto e está aberta ao engajamento e cooperação com outros países.

No âmbito do direito internacional, o Brics manifestou em 2011 sua preocupação com as ameaças terroristas e com a turbulência no Oriente Médio, no Norte e no Oeste da África. Desse modo, reforçou o princípio de que o uso da força deve ser evitado e "que a independência, a soberania, a unidade e a integridade territorial de cada Nação devem ser respeitadas" 32 . Entretanto, em nenhum momento a declaração faz menção expressa aos direitos humanos; apenas afirma:

Acreditamos que o crescimento e o desenvolvimento são fundamentais para enfrentar a pobreza e alcançar as Metas de Desenvolvimento do Milênio. Erradicar a pobreza extrema e a fome é um imperativo moral, social, político e econômico da humanidade e um dos maiores desafios globais que o mundo enfrenta hoje, especialmente os países de menor desenvolvimento relativo na África e em outros continentes ${ }^{33}$.

Isso demonstra que o Brics acredita na premissa de que somente um país desenvolvido e em crescimento é capaz de enfrentar questões relativas aos direitos humanos. Ainda na Terceira Cúpula, o Brics apresentou pela primeira vez um plano de ação, que estabeleceu as bases da cooperação dentro do grupo. Para o objetivo proposto neste artigo, apresentamos a ação que trata do tema direito à saúde.

Especificamente, 2011 teve destaque por ter sido a primeira vez em que o termo "saúde pública" apareceu nas declarações, da seguinte forma: "Sublinhamos nosso firme compromisso em reforçar o diálogo e a cooperação nos domínios da

\footnotetext{
${ }^{31}$ BRICS. Declaração de Sanya - Reunião de Líderes do BRICS Sanya, China, 14 de abr de 2011, China. Disponível em: <http://www.stf.jus.br/repositorio/cms/portalStflnternacional/portalStfCooperacao_pt_ br/anexo/Declaracao_de_Sanya_III_Cupula_do_BRICS.pdf>. Acesso em: 01 agosto 2012.

${ }^{32}$ Id. Ibid.

${ }^{33}$ Id. Ibid.
} 
proteção social, trabalho decente, igualdade de gênero, juventude e saúde pública, incluindo a luta contra o HIV/Aids" ${ }^{34}$. E aqui, de fato, a saúde pode se apresentar como ponte para a cidadania, a qual deverá ser construída sobre os pilares da fraternidade: o pacto entre iguais, o compartilhar, o mediar, a lei da amizade, a não violência e a inclusão universal. Uma das orientações foi a de

mudar a estratégia de cooperação, calcada em programas baseados em uma única orientação global dos doadores, para uma cooperação compartilhada, orientada pelo planejamento estratégico centrado na realidade do país parceiro ${ }^{35}$.

Aqui se percebe claramente a necessidade de ver o outro como outro-eu - um pressuposto fundamental do Direito Fraterno, em que o outro-Estado tem que ser visto como um eu. Assim, a fraternidade não é imposta, trata-se de uma condição.

Nesse ponto, percebe-se que o Brics tem como objetivo, justamente, enfatizar "a cooperação sul-sul e favorece modelos ancorados em programas nacionais e suas próprias filosofias políticas e sociais"'36 (tradução livre). Ou seja, esses países visualizam que existem problemas comuns a todos e que, portanto, podem compartilhar soluções ou buscar respostas conjuntas pela cooperação. Nesse sentido, a cooperação técnica é um diferencial em relação às práticas tradicionais realizadas pelos países ricos, baseada na assistência.

Ademais, em 2011 foram realizados os seguintes eventos: Reunião de Ministros da Saúde do Brics (Pequim, 11 de julho); Encontro de Ministros da Saúde do Brics, à margem da 64a Assembleia Mundial da Saúde (Genebra, 17 de maio); Encontro de Ministros da Saúde do Brics sobre prevenção e controle das doenças não transmissíveis, à margem da Reunião de Alto Nível da ONU sobre Doenças Não Transmissíveis (Nova Iorque, 20 de setembro); Reunião do GT sobre acesso a medicamentos do Brics paralelamente à 29a Reunião do Comitê Gestor do Programa Conjunto das Nações Unidas sobre HIV/Aids (UNAIDS, Genebra, 13 de dezembro) ${ }^{37}$.

Na sequência, durante a Quarta Cúpula identifica-se que o discurso permaneceu basicamente o mesmo de 2011. Porém nela foi considerada pela primeira vez a possibilidade de estabelecer um novo banco de desenvolvimento, voltado à

\footnotetext{
${ }^{34}$ BRICS. Declaração de Sanya - Reunião de Líderes do BRICS Sanya, China, 14 de abr de 2011, China, cit. ${ }^{35}$ BUSS P. M; FERREIRA, J. R. Ensaio crítico sobre a cooperação internacional em saúde. RECIIS - Revista Eletrônica de Comunicação, Informação \& Inovação em Saúde, Rio de Janeiro, v. 4, n. 1, p. 96, mar. 2010. Disponível em: <http://www.reciis.cict.fiocruz.br/index.php/reciis/article/view/350>. Acesso em: 20 ago. 2013. 10.3395/reciis.v4i1.350pt.

${ }^{36}$ No original: "[...] south-south cooperation and they favor models anchored in domestic programs and their own political and social philosophies". GLOBAL HEALTH STRATEGIES INITIATIVES (GHSi). Shifting Paradigm. How the BRICS are Reshaping Global Health and Development. Technical Report. Global Health Strategies Initiatives, New Delhi, 2012. p. 10-11. Disponivel em: <http://researchonline.Ishtm.ac.uk/344111/1/ Shifting\%2OParadigm.\%20How\%20the\%20BRICS\%20are\%20Reshaping\%20Global\%20Health\%20 and\%20Development.pdf>. Acesso em: 12 jul. 2013.

${ }^{37}$ BRICS. Declaração de Sanya - Reunião de Líderes do BRICS Sanya, China, 14 de abr de 2011, China, cit.
} 
mobilização de recursos para projetos de infraestrutura e de desenvolvimento sustentável em países do Brics e em outras economias emergentes e países em desenvolvimento. Com relação à questão dos direitos humanos no direito internacional, os países manifestaram preocupação com a situação na Síria e apelaram pelo fim imediato de toda violência e das violações de direitos humanos naquele país, entre outros temas ${ }^{38}$. Já em termos de inciativas concretas, a Quarta Cúpula do Brics destacou a preocupação com o direito à saúde:

A maioria dos países do Brics faz face aos numerosos desafios similares no campo da saúde pública, incluindo o acesso universal aos serviços de saúde, o acesso a tecnologias de saúde, inclusive medicamentos, os custos crescentes e o aumento nos gastos com doenças transmissíveis e não transmissíveis. Recomendamos que os encontros de Ministros de Saúde do Brics, cujo primeiro realizou-se em Pequim, em julho de 2011, sejam de agora em diante institucionalizados de forma a enfrentar esses desafios comuns da maneira mais eficaz em termos de custos, mais equitativa e sustentável ${ }^{39}$. (Destaques nossos.)

Além disso, naquele ano, realizaram-se os seguintes eventos: reunião informal do Brics durante a 130ª sessão do Conselho Executivo da OMS (Genebra, 19 de janeiro); e Encontro de Ministros da Saúde do Brics, às margens da 65ª Assembleia Mundial da Saúde (Genebra, 22 de maio) ${ }^{40}$.

A Quinta Cúpula, realizada em 2013, concluiu o primeiro ciclo de cúpulas do Brics e reiterou muitas questões relativas ao desenvolvimento mais equitativo e ao crescimento global mais inclusivo abordadas nas anteriores. Desse modo, sua declaração trouxe inúmeras questões relativas à economia mundial, bem como uma crítica às ações políticas adotadas na Europa, nos EUA e no Japão, por produzirem efeitos colaterais negativos nas demais economias ${ }^{41}$. Os países do Brics também reafirmaram o compromisso de trabalhar conjuntamente para alcançar os Objetivos do Milênio. Ainda em 2013, foi realizado o Encontro de Altos Funcionários em Saúde (Nova Déli, 10 de janeiro), prévio ao II Encontro de Ministros da Saúde (Nova Déli, 11 de janeiro $)^{42}$. Ainda em 2013, foi adotado o Marco do Brics para a Colaboração em Projetos Estratégicos em Saúde.

\footnotetext{
${ }^{38}$ BRICS. Quarta Cúpula do Brics: Nova Delhi, 29 de março de 2012 Parceria do Brics para a Estabilidade, Segurança e Prosperidade - Declaração de Nova Delhi. Nota n. 77. Nova Delhi, 29 mar. 2012. Disponível em: <http://brics.itamaraty.gov.br/pt-br/categoria-portugues/20-documentos/76-quarta-declaracaoconjunta>. Acesso em: 01 ago. 2012.

${ }^{39}$ Id. Ibid.

${ }^{40}$ Id. Ibid.

${ }^{41}$ Id. Ibid.

${ }^{42}$ Id. Ibid.
} 
A respeito das questões de direitos humanos, a Quinta Cúpula condenou o aumento das violações de direitos humanos e do direito humanitário internacional como resultado da continuidade da violência. Além disso, os países conclamaram a comunidade internacional a ajudar Israel e Palestina a trabalharem em direção a uma solução de dois Estados e apresentaram novamente questões como o compromisso com o Afeganistão e a questão nuclear no Irã, a preocupação com a deterioração das questões humanitárias no Mali e com a instabilidade em curso na República Democrática do Congo. Todas essas questões humanitárias voltaram a ser tratadas nas duas cúpulas seguintes, de 2014 e 2015 - com destaque para 2015, cuja declaração expressou apoio aos passos dados pela Federação da Rússia voltados à promoção de uma solução política na Síria. Novamente aqui vemos a necessidade de cooperarmos, de sermos fraternos, de buscarmos soluções com outros pressupostos, como o da fraternidade.

A Sexta Cúpula deu início ao segundo ciclo do Brics, após cada país-membro ter sediado uma reunião de líderes. Marcos importantes de 2014 foram: a adoção da Declaração e Plano de Ação de Fortaleza; a criação do Novo Banco de Desenvolvimento; o estabelecimento de um Arranjo Contingente de Reservas do Brics; e a assinatura de acordos de cooperação entre bancos de desenvolvimento dos países do Brics e entre suas agências de seguro de crédito à exportação ${ }^{43}$.

$\mathrm{Na}$ área da saúde, a Sexta Cúpula instruiu os institutos nacionais de estatística e os ministérios da Saúde e da Educação a trabalharem no desenvolvimento de metodologias conjuntas para a criação de indicadores sociais, a serem incorporadas na publicação estatística conjunta do Brics - e o Conselho de Think Tanks do Brics (BTTC) foi encorojado a prestar apoio técnico nessa tarefa ${ }^{44}$.

A Sexta Cúpula foi considerada "decepcionante" em termos de proteção aos direitos humanos, legando uma grande preocupação com ênfase puramente econômica, especialmente em relação ao tipo de financiamento promovido pelo Banco do Brics.

Por fim, a Sétima Cúpula abordou temas como migração, combate à corrupção e estratégias de parceria econômica. Na declaração de 2015, todavia, a área da saúde ganhou destaque: reiterou-se a preocupação com um alto padrão de saúde física e mental, com as ameaças globais de doenças transmissíveis e não transmissíveis, com a implementação do acesso universal e equitativo a serviços de saúde e com o alastramento de doenças graves (HIV/Aids, tuberculose, malária e outras),

\footnotetext{
${ }^{43}$ BRICS. V Cúpula do BRICS - Durban, 27 de março de 2013 - BRICS e África: Parceria para o Desenvolvimento, Integração e Industrialização - Declaração de e-Thekwini. Durban, 2013. Disponível em: <http://www. itamaraty.gov.br/notas-a-imprensa/3371-v-cupula-do-brics-durban-27-de-marco-de-2013-brics-e-africaparceria-para-o-desenvolvimento-integracao-e-industrializacao-declaracao-de-e-thekwini>. Acesso em: 01 ago. 2012.

${ }^{44}$ Id. Ibid.
} 
bem como com a emergência de infecções de potencial pandêmico (tais como a gripe de alta patogenicidade, o novo coronavírus e o ebola $)^{45}$. Para enfrentar esses desafios globais de saúde e garantir que os países do Brics contribuíssem conjuntamente para fortalecer a segurança sanitária global, o grupo se propôs a trabalhar conjuntamente em áreas como:

- Gestão de riscos relacionados a infecções emergentes com potencial pandêmico;

- Cumprimento de compromissos para evitar o alastramento, bem como erradicar, doenças transmissíveis que afetam o desenvolvimento (HIV/Aids, tuberculose, malária, doenças tropicais "negligenciadas", poliomielite, sarampo);

- Pesquisa, desenvolvimento, produção e oferta de medicamentos voltados a proporcionar maior acesso à prevenção e ao tratamento de doenças transmissíveis ${ }^{46}$.

A declaração de 2015 chama a atenção por afirmar que o Brics dará a mesma atenção a todos os direitos humanos - civis, políticos, econômicos, sociais e culturais, bem como o direito ao desenvolvimento - e que fará esforços para apoiar o diálogo construtivo e não politizado sobre direitos humanos, em uma inclusão sem limites e, portanto, fraterna. Em termos de direitos civis e políticos, ganhou destaque na agenda o direito à privacidade, à comunicação e à informação. Nesse sentido, o grupo afirmou ser inadmissível o uso de tecnologias de informação e comunicação e a internet para a violação dos direitos humanos e das liberdades fundamentais, definindo que a internet é um recurso global e que os Estados devem participar em condição de igualdade de sua evolução e seu funcionamento. Tal posicionamento refletia o repúdio a descobertas de espionagem realizada pelos EUA a fim de obter informações do governo brasileiro.

Pode-se identificar um discurso essencialmente político nas declarações de cúpula do Brics. Os cinco países denominam-se um grupo que visa a contribuir para o desenvolvimento da humanidade e para o estabelecimento de um mundo mais justo e equânime. Todavia, é possível compreender que esse mundo mais equânime busca uma maior participação e voz desses países emergentes perante a comunidade internacional.

Ademais, a partir das declarações das cúpulas pode-se observar, ainda que de forma restrita, que os países do Brics estão dispostos a se comprometer com uma pauta de proteção aos direitos humanos. Contudo, a maioria das questões relativas aos direitos humanos diz respeito a violações presenciadas em países externos ao

\footnotetext{
${ }^{45}$ BRICS. VI Cúpula: Declaração e Plano de Ação de Fortaleza. Fortaleza, 2014. Disponível em: <http:// www.itamaraty.gov.br/pt-BR/notas-a-imprensa/5704-vi-cupula-brics-declaracao-de-fortaleza-15-de-julhode-2014>. Acesso em: 12 out. 2015.

${ }^{46}$ Id. Ibid.
} 
Brics, e muito pouco se fala sobre a garantia desses direitos no âmbito interno de cada país do grupo. Dentro dos direitos sociais, o direito à saúde destaca-se na agenda de cooperação do Brics e, portanto, apresenta-se como uma possibilidade de buscar um novo modelo de cooperação que contribua para a efetivação dos direito humanos.

Apesar da importância das declarações conjuntas e, especialmente dos comunicados oficiais das reuniões dos ministros da Saúde do Brics (realizadas a partir de $2011^{47}$ e que demonstram a preocupação dos países com essa área), até o momento não foi firmado acordo bilateral algum entre o Brasil e outro país do Brics, nem mesmo um acordo multilateral entre os países, para a concretização de uma cooperação na área da saúde ${ }^{48}$. O que se tem de mais recente, até o momento atual, são o Plano de Ação Conjunta entre o Governo da República Federativa do Brasil e o Governo da República Popular da China 2010-2014, no qual a saúde é apenas um tema transversal, e o Memorando de Entendimento em Cooperação na Área de Saúde e Medicina entre o Governo da República Federativa do Brasil, o Governo da República da Índia e o Governo da República da África do Sul, datado de 17 de outubro de 2007, porém no âmbito do IBAS (Índia, Brasil e África do Sul).

Apesar da falta de ações concretas em saúde, o Brics reconhece que a cooperação pode contribuir para um maior desenvolvimento e mais proteção social da população de cada um dos cinco países. Ademais, alguns avanços já foram realizados, especificamente no Brasil, em relação a alguns temas pautados pelas cúpulas do Brics no tocante ao direito à saúde; por exemplo, o Brasil já atingiu as metas de 2015 dos Objetivos do Milênio (ODM), de parar e reverter a incidência e a mortalidade da tuberculose ${ }^{49}$, além de ter avançado no combate ao tabaco (em 2011, foi sancionada a Lei n. $12.546^{50}$, que altera a sistemática de tributação do IPI e institui

\footnotetext{
${ }^{47}$ BRICS Health Ministers' Meeting: Beijing Declaration. Beijing, China, July 11, 2011. BRICS Information Centre. Disponível em: <http://www.brics.utoronto.ca/docs/110711-health.html>. Acesso em: 17 ago. 2013.

${ }^{48}$ Cumpre destacar que a pauta da cooperação brasileira conduzida pelo Ministério da Saúde ainda tem como foco os países da América Latina e os países africanos de língua portuguesa. COOPERAÇÃO Internacional. Portal da Saúde, 19 set. 2013. Disponível em: <http://portalsaude.saude.gov.br/index.php/o-ministerio/ principal/leia-mais-o-ministerio/282-aisa-raiz/aisa/I3-aisa/402-cooperacao-internacional-em-saude>. Acesso em: 01 ago. 2016.

${ }^{49}$ COMBATE à tuberculose ganha adesão de artistas em audiência na Câmara. Portal da Saúde, 08 out. 2015. Disponível em: <http://portalsaude.saude.gov.br/index.php/o-ministerio/principal/secretarias/ svs/noticias-svs/20071-combate-a-tuberculose-ganha-adesao-de-artistas-em-audiencia-na-camara>. Acesso em: 01 ago. 2016.

${ }^{50}$ BRASIL. Lei n. 12.546, de 14 de dezembro de 2011. Institui o Regime Especial de Reintegração de Valores Tributários para as Empresas Exportadoras (Reintegra); dispõe sobre a redução do Imposto sobre Produtos Industrializados (IPI) à indústria automotiva; altera a incidência das contribuições previdenciárias devidas pelas empresas que menciona; altera as Leis $n^{\circ} 11.774$, de 17 de setembro de 2008, $n^{\circ} 11.033$, de 21 de dezembro de 2004, $n^{\circ} 11.196$, de 21 de novembro de 2005, $n^{\circ} 10.865$, de 30 de abril de 2004, $n^{\circ} 11.508$, de 20 de julho de 2007, n० 7.291, de 19 de dezembro de 1984, $n^{\circ} 11.491$, de 20 de junho de 2007, $n^{\circ}$ 9.782, de 26 de janeiro de 1999, e n'9.294, de 15 de julho de 1996, e a Medida Provisória $n^{\circ} 2.199$ 14, de 24 de agosto de 2001; revoga o art. $1^{\circ}$ da Lei $n^{\circ} 11.529$, de 22 de outubro de 2007 , e o art. $6^{\circ}$ do Decreto-Lei n ${ }^{\circ}$ 1.593, de 21 de dezembro de 1977, nos termos que especifica; e dá outras providências. Disponível em: <http://www.planalto.gov.br/ccivil_03/_ato2011-2014/2011/lei/l12546.htm>. Acesso
} 
uma política de preços mínimos para os cigarros; em dezembro de 2014, o fumo em ambientes fechados foi vedado em todo o país e a publicidade de produtos com tabaco, proibida em todo o território nacional ${ }^{51}$ ).

Destaca-se que o Brics está avançando em outras ações. Por exemplo, em 2015 foram realizados 2 Seminário de Funcionários e Peritos em Questões Populacionais do Brics e a $1^{\text {a }}$ Reunião de Ministros Responsáveis por Assuntos Populacionais do Brics, que debateram, entre outros temas, mortalidade materna, Aids e doenças sexualmente transmissíveis ${ }^{52}$.

\section{Considerações finais}

Temos de avançar, então, na pesquisa da solidariedade. Esta aparece em tempos diversos, não conhece caminhos lineares, mas revela uma capacidade permanente de forçar a barreira dentro da qual se busca fechá-la. E se converte em uma importante força positiva e assume também a forma da fraternidade (da qual é tida muitas vezes como sinônima) e, assim como a liberdade e a igualdade, no entanto, está lá, no panteão revolucionário, como evocação de uma solidariedade universal, social ${ }^{53}$. (Tradução livre.)

Efetivamente não é simples nem automático encontrar o outro, pois, para tanto, precisamos não apenas aceitar o outro e caminhar com ele, mas viver entre e com o outro. Como farão os países do Brics para se abrirem para essa nova postura, tão necessária a uma agenda comum? Quais fatores podem contribuir nesse desafio? Este artigo propõe a efetivação da saúde - sendo este um direito humano - como um possível meio de aproximação, cooperação, integração e interligação entre os países, já que a saúde pode ultrapassar - e ultrapassa - fronteiras e barreiras.

Aprendemos com Amartya $\operatorname{Sen}^{54}$ que a prática da democracia oferece aos cidadãos a possibilidade de aprender uns com os outros e a sociedade, de formar os próprios valores e de definir as próprias prioridades. Mas, além desse aprendi-

em: 13 out. 2017.

${ }^{51}$ MINISTRO da Saúde participa de conferência mundial sobre tabaco. Portal da Saúde, 27 abr. 2015. Disponível em: <http://portalsaude.saude.gov.br/index.php/o-ministerio/aisa/noticias-aisa/17512ministro-da-saude-participa-de-conferencia-mundial-sobre-tabaco>. Acesso em: 01 ago. 2016.

${ }^{52}$ ENCONTRO do Brics discute mortalidade materna. Governo do Brasil. Portal Brasil, 12/02/2015. Disponível em: <http://www.brasil.gov.br/governo/2015/02/encontro-do-brics-discute-mortalidade-materna>. Acesso em: 01 ago. 2016.

${ }^{53}$ No original: "Bisogna muoversi, allora, alla ricerca della solidarierà. Questa compare in tempi diversi, non conosce traggiti lineari, ma rivela una capacità permanente di forzare le barriere entro le quali si cerca di chuiderla. E si converte così in una potente forza positive, assume anche le sembianze della fraternità (di cui sovente è presentata come sinonimo) e così, insieme a libertà ed eguaglianza, comunque sta lì, nel pantheon rivoluzionario, come evocazione di una solidarietà universale, sociale". RODOTÀ, Stefano. Solidarietà un'utopia necessaria . Bari: Laterza, 2014. p. 20.

${ }^{54}$ SEN, Amartya. op. cit., p. 63. 
zado, temos que aprender a entender países que não se apresentam democráticos, que possuem outras formas históricas de organização social e política - como é o caso dos países do Brics, em especial o modelo político chinês. Aprender a aprender com o outro significa efetivar a fraternidade: este é o desafio que se apresenta como imperativo neste momento histórico de profundas transformações e ruptura de paradigmas. Como conviver com o diferente? A pergunta continua aberta.

Muito se tem evoluído no combate à violação aos direitos humanos em todos os países, e não seria diferente com os países do Brics. Porém, hoje a agenda de proteção aos direitos humanos proposta pelo Brics reflete muito o interesse de países, como é o caso do Brasil, de serem membros permanentes do Conselho de Segurança da Organização das Nações Unidas.

Ao mesmo tempo, evidencia-se a preocupação com o direito à saúde na agenda de cooperação do Brics e, por isso, muitas iniciativas foram realizadas, com destaque para as duas Reuniões dos Ministros da Saúde dos países do Brics, que definiram áreas prioritárias de cooperação em saúde. O ano de 2011 teve destaque na saúde, pois foi a primeira vez em que o termo "saúde pública" apareceu nas declarações, da seguinte forma: "Sublinhamos nosso firme compromisso em reforçar o diálogo e a cooperação nos domínios da proteção social, trabalho decente, igualdade de gênero, juventude e saúde pública, incluindo a luta contra o HIV/Aids ${ }^{55}$.

Assim, apesar de os países do Brics inicialmente se identificarem por suas taxas de crescimento econômico, acredita-se que, com a evolução do grupo, este pode contribuir para uma nova forma de cooperação. Isso porque ele parte de outra conformação, ou seja, não se trata de "vizinhos iguais" ou de uma integração regional com atitude defensiva, mas sim de países geograficamente distantes e completamente diferentes em termos culturais, econômicos e religiosos e que, apesar das diferenças, vêm demonstrando uma postura ativa, dispostos a conquistar cada vez mais espaço nas relações internacionais e estar mais inseridos nos sistema internacional por meio das organizações mundiais.

Nesse sentido, constata-se que a saúde enquanto direito é o que consegue convergir o grupo para uma agenda comum, pois possibilita a criação de consensos e a construção de um modelo alternativo de cooperação. Isso deve fazer com que os membros do grupo estabeleçam condições para que esse direito se concretize. Resta afirma que o Direito Fraterno vive de esperas cognitivas, e não de arrogâncias normativas ${ }^{56}$, o que vai ao encontro da ideia de cooperação como forma de efetivação de direitos humanos. No caso do direito à saúde, este se afirma como uma ponte, na qual os pressupostos da fraternidade podem se revelar mais plenamente.

\footnotetext{
${ }^{55}$ BRICS. Declaração de Sanya - Reunião de Líderes do BRICS Sanya, China, 14 de abr de 2011, China, cit.

${ }^{56}$ RESTA, Eligio. 0 direito fraterno, cit., p. 135-136.
} 


\section{Referências}

BONANATE, Luigi. Política dos Blocos. In: BOBBIO, Norberto; MATTEUCCI, Nicola; PASQUINO, Gianfranco (Orgs.). Dicionário de política. Tradução de Carmen C. Varriale et al. 12. ed. Brasília-DF: Ed. da UnB; São Paulo: Imprensa Oficial do Estado, 2002.

BRICS. Reunião dos Ministros das Relações Exteriores em Ecaterimburgo, 2008. Ecaterimburgo, 16 de maio de 2008. Disponível em: <http://brics.itamaraty.gov.br/pt-br/ categoria-portugues/20-documentos/184-reuniao-dos-ministros-das-relacoes-exterioresem-ecaterimburgo-2008>. Acesso em: 01 out. 2013.

. First Summit: Joint Statement of the BRIC Countries Leaders. Yekaterinburg, 2009. Disponível em: $<$ http://brics.itamaraty.gov.br/index.php?option=com_content\&view=arti cle\&id=114:first-summit-2\&catid=21:documents\&Itemid=288>. Acesso em: 21 jul. 2013.

. II Second Summit: Joint Statement. Brasília, DF, 16 abr. 2010. Disponível em: <http:// brics.itamaraty.gov.br/press-releases/21-documents/66-second-summit>. Acesso em: 01 ago. 2012.

. Declaração de Sanya - Reunião de Líderes do BRICS Sanya, China, 14 de abr de 2011, China. Disponível em: <http://www.stf.jus.br/repositorio/cms/portalStfInternacional/ portalStfCooperacao_pt_br/anexo/Declaracao_de_Sanya_III_Cupula_do_BRICS.pdf $>$. Acesso em: 01 agosto 2012.

. Quarta Cúpula do Brics: Nova Delhi, 29 de março de 2012 Parceria do Brics para a Estabilidade, Segurança e Prosperidade - Declaração de Nova Delhi. Nota n. 77. Nova Delhi, 29 mar. 2012. Disponível em: <http://brics.itamaraty.gov.br/pt-br/categoria-portugues/20documentos/76-quarta-declaracao-conjunta>. Acesso em: 01 ago. 2012.

. V Cúpula do BRICS - Durban, 27 de março de 2013 - BRICS e África: Parceria para o Desenvolvimento, Integração e Industrialização - Declaração de e-Thekwini. Durban, 2013. Disponível em: <http://www.itamaraty.gov.br/notas-a-imprensa/3371-v-cupula-do-bricsdurban-27-de-marco-de-2013-brics-e-africa-parceria-para-o-desenvolvimento-integracaoe-industrializacao-declaracao-de-e-thekwini >. Acesso em: 01 ago. 2012.

VI Cúpula: Declaração e Plano de Ação de Fortaleza. Fortaleza, 2014. Disponível em: $<$ http://www.itamaraty.gov.br/pt-BR/notas-a-imprensa/5704-vi-cupula-brics-declaracao-defortaleza-15-de-julho-de-2014>. Acesso em: 12 out. 2015.

BRICS Health Ministers' Meeting: Beijing Declaration. Beijing, China, July 11, 2011. BRICS Information Centre. Disponível em: <http://www.brics.utoronto.ca/docs/110711-health. html>. Acesso em: 17 ago. 2013.

BRICS. Disponível em: <http://www2.stf.jus.br/portalStfInternacional/cms/verConteudo. php?sigla=portalStfCooperacao_pt_br\&idConteudo=159618>. Acesso em: 1 ago. 2012.

BUSS P. M; FERREIRA, J. R. Ensaio crítico sobre a cooperação internacional em saúde. RECIIS - Revista Eletrônica de Comunicação, Informação \& Inovação em Saúde, Rio de Janeiro, v. 4, n. 1, p. 93-105, mar. 2010. Disponível em: <http://www.reciis.cict.fiocruz. br/index.php/reciis/ article/view/350>. Acesso em: 20 ago. 2013. 10.3395/reciis.v4i1.350pt. 
BUSS, P. M. Globalização, pobreza e saúde. Ciência e Saúde Coletiva, Rio de Janeiro, v. 12, n. 6, nov./dec. 2007. Disponível em: <http://www.scielo.br/pdf/csc/v12n6/v12n6a17.pdf>. http://dx.doi.org/10.1590/S1413-81232007000600019.

CHEVALLIER, Jacques. O Estado pós-moderno. Tradução Marçal Justen Filho. São Paulo: Fórum, 2009.

COMBATE à tuberculose ganha adesão de artistas em audiência na Câmara. Portal da Saúde, 08 out. 2015. Disponível em: <http://portalsaude.saude.gov.br/index.php/o-ministerio/ principal/secretarias/svs/noticias-svs/20071-combate-a-tuberculose-ganha-adesao-deartistas-em-audiencia-na-camara $>$. Acesso em: 01 ago. 2016.

COOPERAÇÃO Internacional. Portal da Saúde, 19 set. 2013. Disponível em: <http:// portalsaude.saude.gov.br/index.php/o-ministerio/principal/leia-mais-o-ministerio/282aisa-raiz/aisa/13-aisa/402-cooperacao-internacional-em-saude>. Acesso em: 01 ago. 2016.

DEBORD, GUY. Sociedade do espetáculo. Rio de Janeiro: Contraponto, 2007.

ENCONTRO do Brics discute mortalidade materna. Governo do Brasil. Portal Brasil, 12/02/2015. Disponível em: <http://www.brasil.gov.br/governo/2015/02/encontro-do-bricsdiscute-mortalidade-materna $>$. Acesso em: 01 ago. 2016.

GLOBAL HEALTH STRATEGIES INITIATIVES (GHSi). Shifting Paradigm. How the BRICS are Reshaping Global Health and Development. Technical Report. Global Health Strategies Initiatives, New Delhi, 2012.p. 10-11. Disponível em: $<$ http://researchonline.lshtm. ac.uk/344111/1/Shifting\%20Paradigm.\%20How\%20the\%20BRICS\%20are\%20Reshaping\%20 Global\%20Health\%20and\%20Development.pdf >. Acesso em: 12 jul. 2013.

HURREL, Andrew. Hegemonia, liberalismos e ordem global: qual é o espaço para potências emergentes? In: HURREL, Andrew et al. (OrgS.). Os Brics e a ordem global. Rio de Janeiro: FGV, 2009.

INNERARITY, Daniel. Ética de la hospitalidad. Barcelona: Península, 2001.

MINISTRO da Saúde participa de conferência mundial sobre tabaco. Portal da Saúde, 27 abr. 2015. Disponível em: <http://portalsaude.saude.gov.br/index.php/o-ministerio/aisa/ noticias-aisa/17512-ministro-da-saude-participa-de-conferencia-mundial-sobre-tabaco $>$. Acesso em: 01 ago. 2016.

PROGRAMA DAS NAÇÕES UNIDAS PARA O DESENVOLVIMENTO (PNDUD). Os objetivos de desenvolvimento do milênio. Brasília, DF, 2012. Disponível em: <http://www. pnud.org.br/ODM.aspx>. Acesso em: 21 jul. 2013.

Relatório do Desenvolvimento Humano de 2015. Brasília, DF, 2015. Disponível em: $<$ http://www.br.undp.org/content/brazil/pt/home/library/relatorios-de-desenvolvimentohumano/relatorio-do-desenvolvimento-humano-200014.html>. Acesso em: 30 out. 2017.

RESTA, Eligio. Diritto vivente. Bari: Laterza, 2013. 
RESTA, Eligio. O direito fraterno. Tradução e coordenação de Sandra Regina Martini. Santa Cruz do Sul: EDUNISC, 2004.

RODOTÀ, Stefano. Il diritto di avere diritti. Bari: Laterza, 2012. . Solidarietà un'utopia necessaria . Bari: Laterza, 2014.

SEN, Amartya. A ideia de justiça. São Paulo: Companhia das letras, 2011.

VENTURA, Deisy de Freitas Lima. Uma visão internacional do direito à saúde. In: SOUSA JUNIOR, José Geraldo de; FONSECA, Lívia Gimenes Dias da; APOSTOLOVA, Bistra Stefanova (Orgs.). O direito achado na rua. Brasília, DF: CEAD/UNB, 2008. v. 4.

VIAL, Sandra Regina Martini. O pressuposto da fraternidade como condição para a efetivação do direito à saúde. In: AITH, Fernando et al. (Orgs.). Direito sanitário: saúde e direito, um diálogo possível. Belo Horizonte: Escola de Saúde Pública do Estado de Minas Gerais, 2010.

VISENTINI. Paulo Fagundes. Brics, OCX e Ibas: as coalizões dos emergentes. In: VISENTINI. Paulo et al. (Orgs.). Brics, as potências emergentes. 1. ed. Petrópolis: Vozes, 2013.

Sandra Regina Martini - Pós-Doutora em Direito pela Università degli studi di Roma Tre; doutora em Direito no programa Evoluzione dei Sistemi Giuridici e Nuovi Diritti (Evolução do Sistema Jurídico e o Novo Direito) da Università Degli Studi di Lecce. Professora do Centro Universitário Ritter dos Reis (Uniritter) e professora-visitante no Programa de Pós-Graduação em Direito da Universidade Federal do Rio Grande do Sul (UFRGS). Porto Alegre/RS, Brasil. E-mail: srmvial@terra.com.br.

Marina Sanches Wünsch - Doutoranda em Estudos Estratégicos Internacionais na Universidade Federal do Rio Grande do Sul; mestre em Direito pelo Programa de Pós-Graduação em Direito da Universidade do Vale do Rio dos Sinos. Professora na Faculdade de Integração do Ensino Superior do Cone Sul (Fisul). Porto Alegre/RS, Brasil.E-mail: marinawunschs@gmail.com. 